\title{
Soil moisture monitoring in the Toce valley (Italy)
}

\author{
M. Menziani ${ }^{1}$, S. Pugnaghi ${ }^{1}$, S. Vincenzi ${ }^{2}$ and R. Santangelo ${ }^{1}$ \\ ${ }^{1}$ Dipartimento di Ingegneria dei Materiali e dell’Ambiente - Osservatorio Geofisico, Università di Modena e Reggio Emilia, Via Vignolese 905 , I-41100 Modena, Italy \\ ${ }^{2}$ ISMAR-istituto di Scienze Marine, Dinamica grandi masse, S. Polo 1364, I-30125 Venezia, Italy \\ Email for corresponding author: marilena.menziani@unimo.it
}

\begin{abstract}
In the framework of the Mesoscale Alpine Programme (MAP), soil water content profiles were collected at a point station in the Toce Valley (Lago Maggiore MAP Target Area). The data are for the first $70 \mathrm{~cm}$ depth of soil for the period April-November, 1999. All measurements were made by a Time Domain Reflectometry device. The time variation of the water stored in a column of soil was estimated by a mass balance method. Evaporation was estimated from the data collected in the summer period. Likewise, by applying the mass balance method to the data collected during and after heavy precipitation events, the water infiltrated into the soil was also estimated. A qualitative evaluation of ponding and/or runoff as the difference between the precipitated and the drained water was obtained under suitable assumptions. Furthermore, the time evolution of the soil water content profile was studied by solving the Richards equation both analytically and numerically for two particular cases: the driest period and a period following a heavy precipitation event. Finally, during the MAP Special Observing Period, two intensive campaigns were performed, together with measurements using an airborne passive microwave radiometer, to assess the spatial distribution of the surface $(0-30 \mathrm{~cm}$ depth) soil water content in fields with different physical and agricultural characteristics.
\end{abstract}

Keywords: soil water content, Time Domain Reflectometry, TDR temperature-dependence, evaporation, infiltration, runoff, linearised Richards equation.

\section{Introduction}

The MAP Special Observing Period (SOP), 7 September15 November 1999, was a very large experimental effort over the mountain range of the Alps. The Ticino-Toce catchment (CH-I), in the core of the Lago Maggiore MAP Target Area, is one of the Alpine areas chosen for the observational campaign and the flood forecast. Indeed, it is well known that the local precipitation maxima (both for precipitation amounts and for frequency of heavy precipitation) of the southern slope of the Alps are connected with indentations in the mountain range (Binder and Schär, 1996; Bougeault et al., 1998). One of these maxima coincides with the Lago Maggiore area (Canton Ticino and northern part of the Piedmont Region). Several Italian teams (Hydrology Working Group and Planetary Boundary Layer Working Group) have operated jointly in this target area. During the MAP-SOP these teams tackled one of the Map scientific objectives: to study how soil water content prior to flood events determines the production of runoff and to investigate the capability and limitations of some soil water content monitoring techniques over rugged terrain. To achieve this goal, some open and flat areas with bare soil or short vegetation were selected for soil water content measurements in the Toce Valley.

The measurements were collected by the Research Unit (RU) of the Osservatorio Geofisico (University of Modena and Reggio Emilia) and relate to the first $70 \mathrm{~cm}$ of soil, using the Time Domain Reflectometry (TDR) technique. TDR is a relatively new technique for measuring soil water content; it is based on measuring the apparent dielectric constant of the soil from the propagation velocity of an electromagnetic pulse travelling in the soil. Soil water content is then calculated from the apparent dielectric constant through empirical relationships (Topp et al.,1980; Roth at al., 1990; Heimovaara, 1993; Heimovaara and de Water, 1993) or from look-up tables (LUTs) with experimentally-determined values (Soilmoisture, 6050X1 Operating Instructions, 2000). In this study, Soilmoisture LUTs for the buriable and connector probes are used.

TDR soil water content measurements are not yet 
frequently available and are not commonly used to monitor soil-atmosphere coupling. Such observations enable study of the influence of the soil water content on evapotranspiration fluxes (owing to its effect on the surface albedo and on the partitioning between sensible and latent heat fluxes) and on runoff following heavy precipitation.

\section{The field set up}

The water content profile from the surface to $70 \mathrm{~cm}$ depth was monitored in a wide meadow opposite the hydropower plant of Pallanzeno (Long. 8.260 ${ }^{\circ}$ E, Lat. $46.047^{\circ} \mathrm{N}$ ), in the Toce River Valley. There, an automatic station was installed with 15 buriable probes connected to the TDR system (Soilmoisture Equipment Corp.) by a multiplexer. Twelve probes were installed horizontally at : 5, 7.5, 10, 12.5, 15, 20, 25, 30, 35, 40, 47 and $50 \mathrm{~cm}$ depths. Three probes were installed vertically to measure the mean soil water content of three successive soil layers: 0-20, 25-45 and 50-70 cm. The measurements were collected automatically, starting at the end of March and ending on 15th November 1999 (end of the MAP-SOP). Precipitation data were available from the rain gauge of the nearby hydropower plant.

During April, measurement cycles for all the probes installed at the station were carried out at six-hour intervals to test the whole set-up. No data were collected in May because of an instrumental failure. From the beginning of June to 15 November, the time interval was reduced to four hours - 00, 04, 08, 12, 16, 20 hours (Central European time) - corresponding to a total of 90 measurements a day.

\section{The data record}

The month of April 1999 was characterised by only one heavy precipitation event (59.2 mm on April 15-16). During the first 14 days of the month, the soil showed a drying trend. The heavy precipitation produced a fast rise in soil water content at all the measured depths. From June up to the end of July, soil water content decreased (disregarding the days following the precipitation events). On July 27 the layer nearest the surface (horizontal probe at $5 \mathrm{~cm}$ ) reached the minimum measured soil volumetric water content of $17.7 \%$. August was quite rainy and the soil water content remained almost constant: a new minimum was reached on September 17. On 19, 20 and 21 September (MAP-IOP02 ) a total precipitation of $225.4 \mathrm{~mm}$ produced the maximum soil water content measurement of $56 \%$; this was detected by the probe nearest the surface $(5 \mathrm{~cm})$. This value represents the saturation of the soil investigated (silty loam), indeed it coincides with the value obtained from the porosity measured by Falappi et al. (2000). October shows a new decreasing trend in soil water content till a new precipitation event (76.4 mm) on October 21 (MAP-IOP-08). Thereafter, the soil water content maintains high values at all depths till the end of the measurement period. Figure 1 shows the trend of the daily mean of the soil water content $\theta$ of the

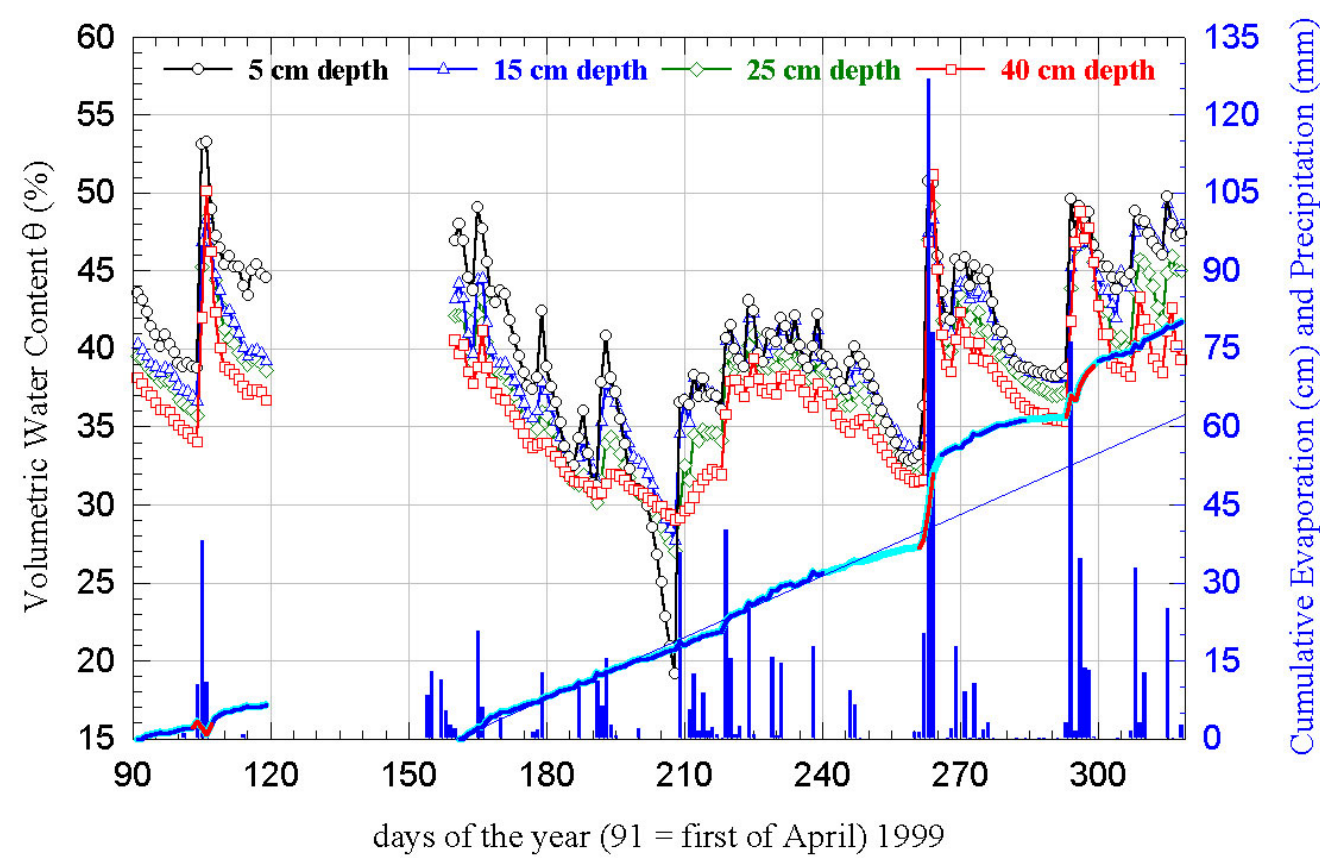

Fig. 1. The trend in daily mean of soil water content $\theta$ for the whole period of measurement: $5 \mathrm{~cm}$ (circle), $15 \mathrm{~cm}$ (triangle), $25 \mathrm{~cm}$ (diamond) and $40 \mathrm{~cm}$ (square). The vertical bars are the daily cumulative precipitation values. The thick solid line represents the cumulative evaporation; the thin straight line is the linear regression of June-August E(t) data. 
whole period. For better comprehension of the figure, data from four probes only are presented.

\section{Intensive field measurements}

During the MAP-SOP the Osservatorio Geofisico RU participated in two intensive field measurements on September 22-23, after the MAP-IOP-02 and on October 28-29, between MAP-IOP-11 and 12. Both sets of measurements were taken only a few days after the two most intensive precipitation events of the SOP; that is IOP-02 and IOP-08. The TDR measurements were carried out manually at the same time as the radiometric measurements performed by a passive microwave radiometer from CNRIROE (Florence, Italy), on board a CH-7 Kompress helicopter (Paloscia et al., 2000). This radiometer flew over many places in the Toce Valley and in particular over two sites where the Osservatorio Geofisico RU was present: the Siberia field, covered in short grass (Long. $8.291^{\circ} \mathrm{E}$; Lat. $46.092^{\circ} \mathrm{N}$ ) and two bare fields close to Anzola (Long. $8.380^{\circ} \mathrm{E}$; Lat. $45.987^{\circ} \mathrm{N}$ ). One of the fields in Anzola had been harrowed after the harvest and was completely bare (Anzola1); in the other stubble was still present (Anzola2). The manual measurements performed in these fields concerned the soil water content in the layer nearest the surface $(0-15 \mathrm{~cm}$ and $0-30 \mathrm{~cm})$. The mean soil water content values with their standard deviations (accounting for the spatial variability) are reported in Table 1. On September 23 the measurements in the $0-15 \mathrm{~cm}$ layer were performed also along the meadow at Pallanzeno (see Table 1). The mean soil water content measured at Pallanzeno is the greatest and that measured at Anzola is always the lowest. Moreover, the upper layer $(0-15 \mathrm{~cm})$ is systematically more moist than the soil immediately below, as can be inferred by comparing the $0-15$ and $0-30 \mathrm{~cm}$ measurements. As can be seen later in Fig. 5 for the Pallanzeno meadow, this is confirmed and explained by the soil water retention functions (Eccel et al., 2000). At Anzola, the difference between the 15 and $30 \mathrm{~cm}$ layers reduced from October 28 to October 29. All the linear regressions of soil water content data versus the spatial co-ordinate clearly indicate a small soil water content decrease towards the Toce River.

\section{Data description}

The main characteristics of the long data record are: a daily cycle, the trend in soil water content during the driest period (July) and the soil water content behaviour during the major precipitation event (IOP-02). Figure 2a shows the soil water content trend at 5, 15, 25, $40 \mathrm{~cm}$ depths for July 1999; the bars represent the four-hour cumulative precipitation. In the second part of July, precipitation is practically absent until the 28th when there was a heavy precipitation. During this dry period, while the soil water content at $40 \mathrm{~cm}$ shows a slight decrease, all the upper probes show a steep decrease, crossing the $40 \mathrm{~cm}$ curve and reaching the lowest values for the entire period of measurement. In particular, on July 27, the $5 \mathrm{~cm}$ probe measured a value for soil water content equal to $17.7 \%$, the minimum value of the whole record. Figure $2 \mathrm{~b}$ shows the soil water content trend at $5,15,25,40 \mathrm{~cm}$ depths for September 1999; again, the bars represent the four-hour cumulative precipitation. September witnessed the major precipitation event (MAP IOP-02). From 19 to 21 a cumulative precipitation of $225.4 \mathrm{~mm}$ was recorded at Pallanzeno and the highest soil water content $(56.0 \%)$ was measured at $5 \mathrm{~cm}$ depth on September 21. In the first part of September, precipitation was almost absent; the soil water content decreased at all the depths but the shallowest probes failed to reach soil water content values lower than the value measured by the $40 \mathrm{~cm}$ probe. Lastly, both Fig. 2a and Fig. $2 \mathrm{~b}$ show a daily cycle in soil water content at all depths.

The daily oscillation, the soil water balance, the hydraulic characteristics of the soil, the soil water content trend during the driest period and the soil water content trend during the first part of the IOP-02 will now be analysed.

Table 1. The mean soil water content values with their standard deviations (accounting for the spatial variability) measured at the Toce Valley sites: Siberia, Anzola and Pallanzeno during the two intensive field campaigns.

\begin{tabular}{lllllll}
\hline & \multicolumn{2}{c}{$\begin{array}{c}\text { Mean Water Content (\%) } \\
(0-15 \text { cm layer })\end{array}$} & \multicolumn{2}{c}{$\begin{array}{c}\text { Mean Water Content (\%) } \\
(0-30 \text { cm layer })\end{array}$} \\
\hline Site name & Sep. 23 & Oct. 28 & Oct. 29 & Sep. 23 & Oct. 28 & Oct. 29 \\
Siberia & $32.1 \pm 4.6$ & $34.3 \pm 4.5$ & $34.0 \pm 4.8$ & ---- & $30.5 \pm 4.4$ & $30.5 \pm 5.6$ \\
Anzola1 & $24.5 \pm 2.3$ & $24.0 \pm 3.1$ & $21.9 \pm 3.0$ & $21.8 \pm 2.2$ & $21.7 \pm 3.0$ & $20.7 \pm 2.5$ \\
Anzola2 & ---- & $27.4 \pm 2.7$ & $25.8 \pm 3.5$ & ---- & $26.6 \pm 2.3$ & $25.0 \pm 3.1$ \\
Pallanzeno & $44.1 \pm 4.3$ & ----- & ---- & ---- & ---- & --- \\
\hline
\end{tabular}




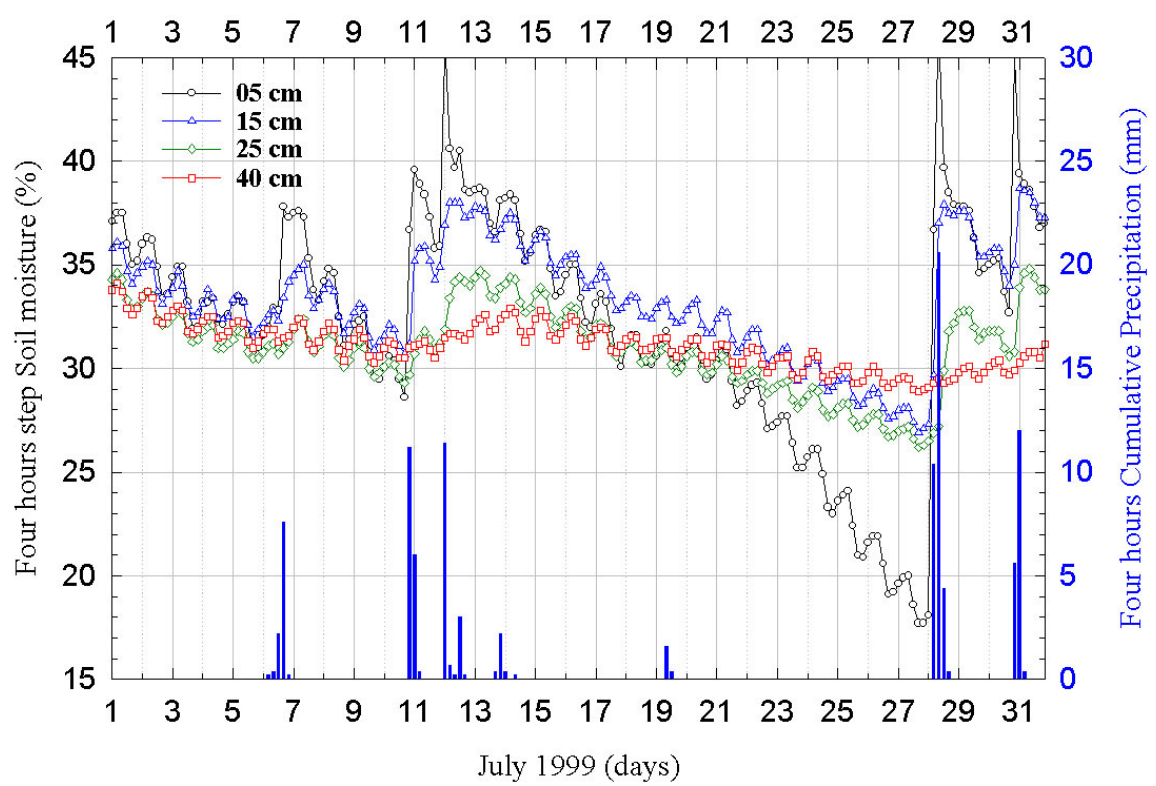

Fig. 2a. Four-hour soil water content trend at 5, 15, 25, $40 \mathrm{~cm}$ depths during July 1999; the bars represent the four-hour cumulative precipitation.

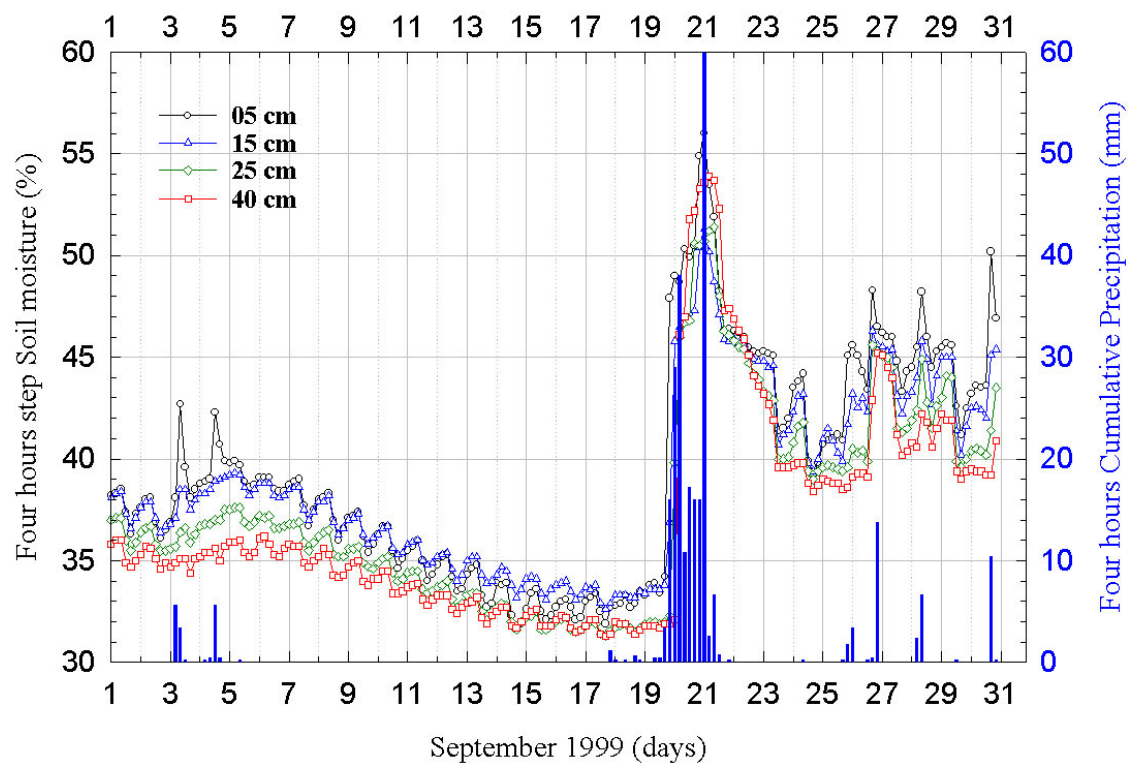

Fig. 2b. Four-hour soil water content trend at 5, 15, 25, $40 \mathrm{~cm}$ depths during September 1999; the bars represent the four-hour cumulative precipitation.

\section{The daily oscillation}

The daily oscillation, present in the experimental soil water content data at all levels (see Figs. 2a and $2 \mathrm{~b}$ as examples), clearly shows non-constant amplitude as against the soil depth while the time delay is quite independent of the depth. To explain this behaviour, a laboratory experiment was carried out; a TDR probe and a PT100 thermometer were set in a container full of river sand (Po River) maintained at saturation. Initially, the sand was heated to about $40^{\circ} \mathrm{C}$, significantly higher than room temperature (about $25^{\circ} \mathrm{C}$ : named $\mathrm{T}_{\text {air }}$ in Fig. 3a and Fig. 3b). Measurements of the sand temperature and of the soil water content were taken simultaneously as the sand cooled to room temperature. The same procedure was repeated after cooling the sand to a temperature (about $10^{\circ} \mathrm{C}$ ) lower than the room temperature. As expected, owing to the dielectric constant temperature dependence (Roth et al., 1990; Pepin et al., 1995; Cahill and Parlange, 1998; Or and Wraith, 1999, 2000;), the TDR 
measurements showed a trend corresponding to the change in soil temperature (see Fig 3a). As can be seen in Fig. 3a, the soil water content and the temperature of the sand show a negative correlation; i.e. an increase in soil temperature means a decrease in the TDR volumetric water content.

In the second part of the experiment the TDR instrument was alternately heated and cooled with respect to room temperature. The TDR soil water content measurements were taken in the saturated sand, maintained at room temperature, while the instrument temperature returned to room temperature. The temperature of the instrument (electronics) and its influence on the TDR measurement are shown in Fig. 3b. This case, too, shows a negative correlation between the temperature of the instrument and the measured soil water content. The temperature of the instrument is the mean value of many infrared measurements taken in different places.

The relationship between the soil water content change

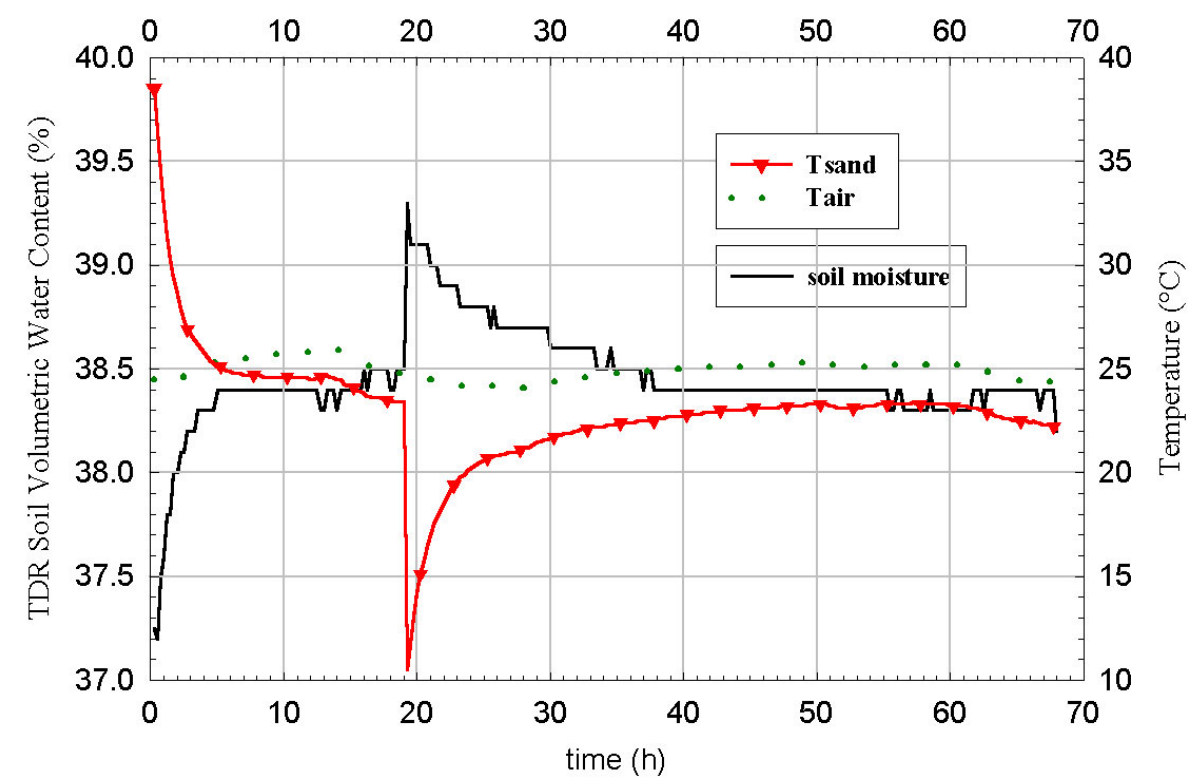

Fig. 3a. TDR soil water content and sand temperature trends during the temperature restoration process (after sand heating and sand cooling). The soil water content and the temperature of the sand show a negative correlation. $T_{\text {air }}$ is the room temperature. The temperature of the sand after the restoration processes is lower than the room temperature because of evaporation.

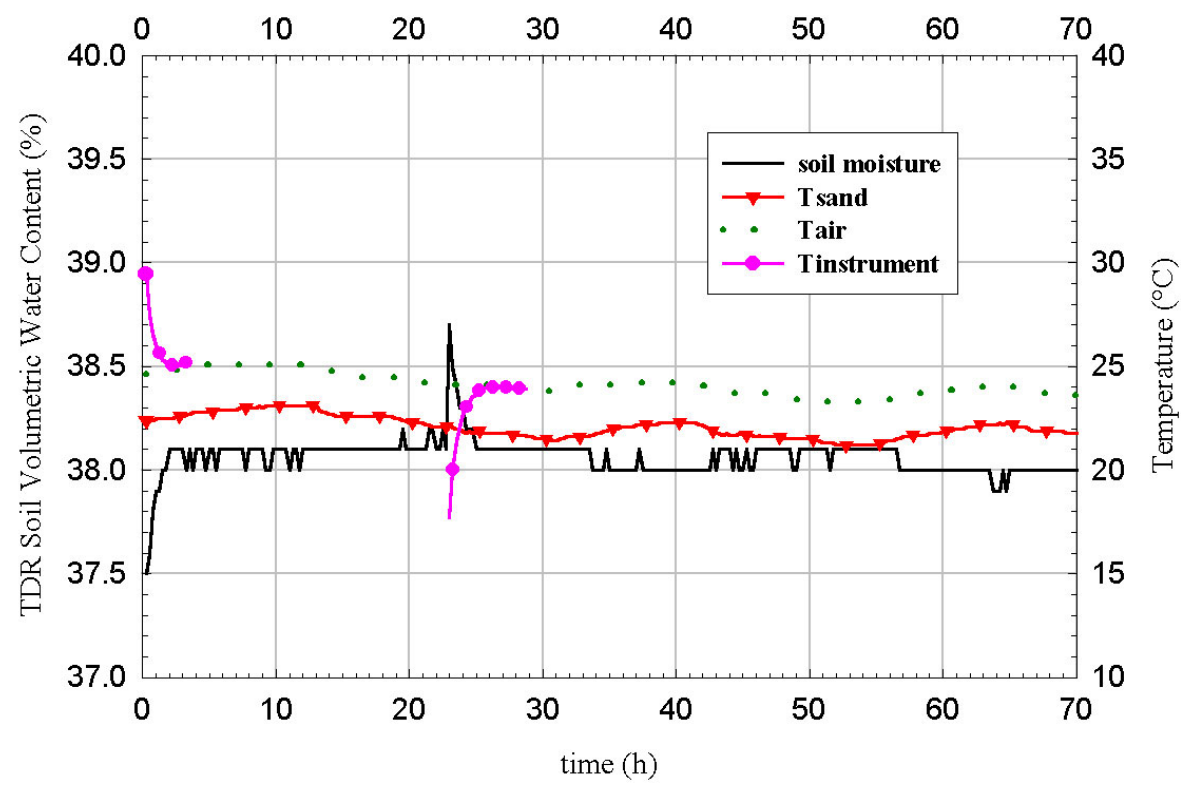

Fig. 3b. TDR soil water content and electronics temperature trends during the temperature restoration process (after instrument heating and cooling). The soil water content and the temperature of the electronics show a negative correlation. $T$ is the room temperature. The temperature of the sand is lower than the room temperature because of evaporation. 
$\Delta \theta$ and the temperature change $\Delta \mathrm{T}$ for both the heating and the cooling processes performed on the sand and on the instrument are reported in Fig. $4 \mathrm{a}$ and in Fig. 4b, respectively. $\Delta \theta$ is the difference between the soil water content measured during the temperature restoring processes and the mean value of the water content at the room temperature. The same holds for $\Delta \mathrm{T}$. The linear regressions of the data of Figs. $4 \mathrm{a}$ and $4 \mathrm{~b}$ give the slope values of $-0.08 \%$ per ${ }^{\circ} \mathrm{C}$ and $-0.10 \%$ per ${ }^{\circ} \mathrm{C}$, respectively.

Unfortunately, the soil temperature profile was not

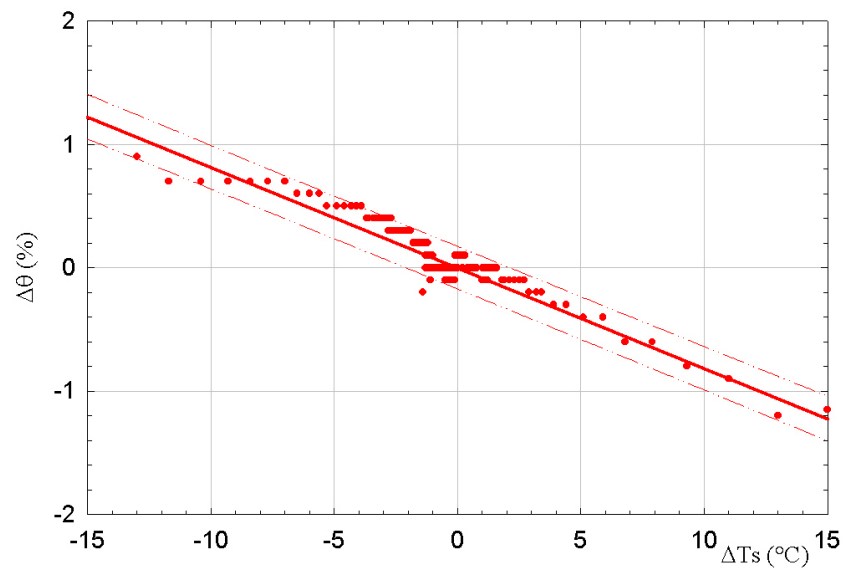

Fig. 4a. Relationship between the soil water content change $\Delta \theta$ and the temperature change $\Delta T$ for both the heating and the cooling processes performed on the sand. $\Delta \theta$ is the difference between the soil water content measured during the temperature restoration processes and the mean value of the water content at room temperature. The same holds for $\Delta T$. The linear regression of the data gives the slope value $-0.08 \% /{ }^{\circ} \mathrm{C}$.

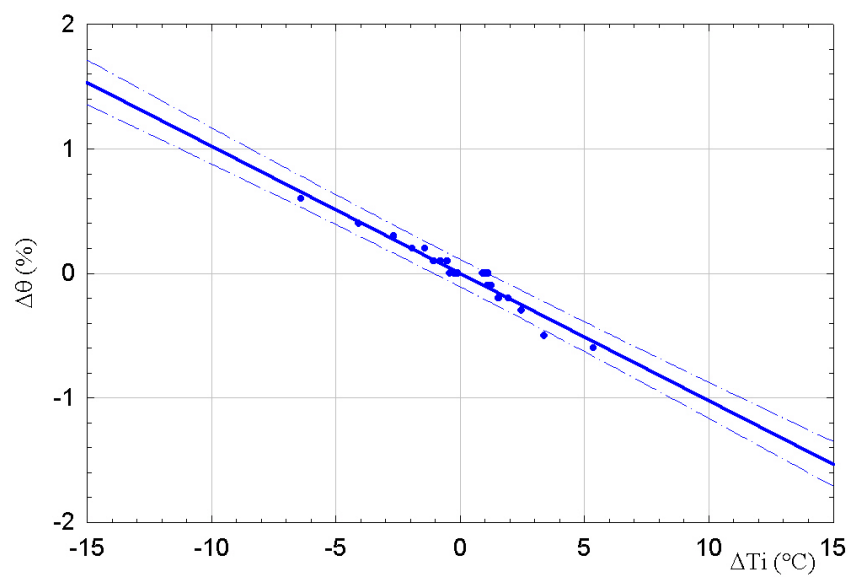

Fig. 4b. Relationship between the soil water content change $\Delta \theta$ and the temperature change $\Delta T$ for both the heating and the cooling processes performed on the instrument. $\Delta \theta$ is the difference between the soil water content measured during the temperature restoration processes and the mean value of the water content at room temperature. The same holds for $\Delta T$. The linear regression of the data gives the slope value $-0.10 \% /{ }^{\circ} \mathrm{C}$.
Table 2. Multiplying factors to fit the daily oscillation of the soil water content data ( $31^{\text {st }}$ March $-4^{\text {th }}$ April; at different depths) by means of the air temperature oscillation assumed to be the instrument one. The mean value of the soil volumetric water content at each depth is also reported.

\begin{tabular}{lcc}
\hline $\begin{array}{l}\text { Depth } \\
(\mathrm{cm})\end{array}$ & $\begin{array}{c}\text { Multiplying Factor } \\
\left(\% /{ }^{\circ} \mathrm{C}\right)\end{array}$ & $\begin{array}{c}\text { Mean Water Content } \\
(\%)\end{array}$ \\
\hline 5 & -0.28 & 43 \\
10 & -0.25 & 42 \\
15 & -0.11 & 40 \\
20 & -0.08 & 39 \\
25 & -0.07 & 39 \\
30 & -0.07 & 38 \\
35 & -0.07 & 38 \\
40 & -0.07 & 38 \\
50 & -0.20 & 42 \\
$50-70$ & -0.12 & 40 \\
\hline
\end{tabular}

measured at the Pallanzeno site. Since the air temperature was available, it was assumed to be the temperature trend of the instrument (certainly under-estimated). Some consecutive days with stable atmospheric conditions (31st March-4th April) were chosen to verify the laboratory results. The daily oscillation with null mean value was obtained from the experimental soil water content and air temperature data. In this period the daily soil water content oscillation is well predicted by fitting the soil water content data by means of the air temperature oscillation with the multiplying factors reported in Table 2 . These multiplying factors should be close to the laboratory recorded slopes (their absolute values were expected to be higher than the

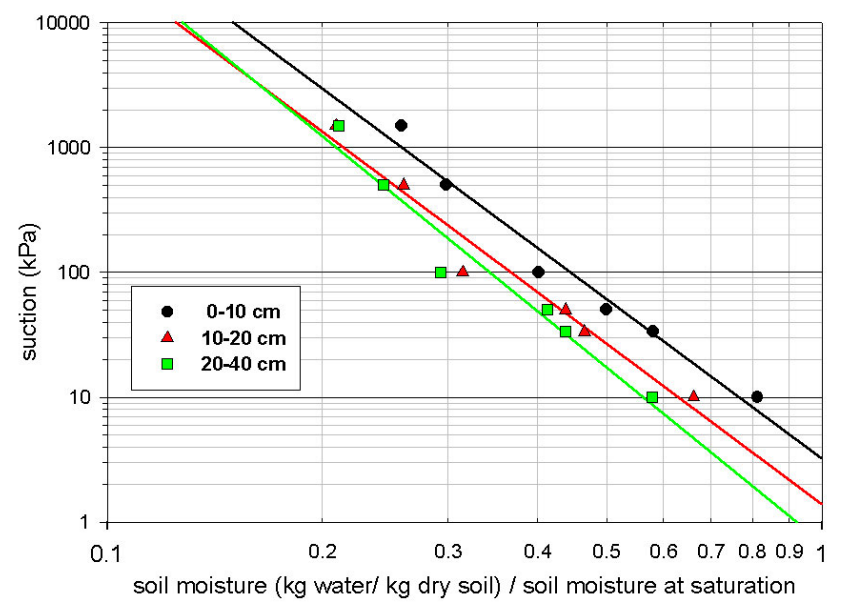

Fig. 5. Soil water retention curves for the three different layers 0-10, 10-20, 20-40 cm of soil sampled at Pallanzeno. The offset and the slope enable the air entry potential $\Psi_{s}$ and the exponent $b$ of power functions (5) to be obtained respectively. 
laboratory results owing to the under-estimated instrument temperature). The mean soil volumetric water content value (of the considered period) at each depth is also reported in Table 2. Clearly, the multiplying factor depends on the soil water content; this implies that the daily oscillation seen in the experimental data is due to the soil conditions and to the thermal trend of the instrument.

\section{The water mass balance}

The water mass balance for a soil column of cross section equal to one and height $\mathrm{H}$ can be described by

$$
\frac{\partial(\rho \cdot \theta)}{\partial t}+\frac{\partial \Phi_{z}}{\partial z}+\left(\operatorname{div}_{h} \Phi_{h}\right)=0
$$

where $\theta$ is the soil volumetric water content, $\rho$ is the water density, $\Phi_{z}$ is the mass flux along the vertical direction $z$ (pointing downward) and the last term is the horizontal divergence of the horizontal flux component.

Integrating Eqn. (1) with respect to $z$ and $t$, the following expression

$$
-L_{H}(t)+\int_{0}^{t} \Phi_{z}\left(H, t^{\prime}\right) \cdot d t^{\prime}+\int_{0}^{t} \int_{0}^{H} d i v_{h} \Phi_{h} d z^{\prime} d t^{\prime}=\int_{0}^{t}\left[p\left(t^{\prime}\right)-e\left(t^{\prime}\right)\right] \cdot d t^{\prime}=P(t)-E(t)
$$

is obtained, where: $L_{H}(t)$, defined as

$$
L_{H}(t)=\int_{0}^{H} \rho \cdot\left[\theta\left(z^{\prime}, 0\right)-\theta\left(z^{\prime}, t\right)\right] \cdot d z^{\prime}
$$

is the soil-water loss from $t=0$ up to $t ; e(t)$ and $p(t)$ are the instantaneous evaporation (or evapotranspiration) and precipitation respectively; $E(t)$ and $P(t)$ are the related cumulative functions.

Assuming the horizontal flux to be negligible and $\Phi_{z}(H, t)=0$, Eqn. (2) becomes

$$
E(t)=L_{H}(t)+P(t)
$$

If drainage or absorption at $z=H$ are present then $E(t)$ from Eqn. (4) represents both cumulative evaporation and drainage or absorption.

$E(t)$ is expected to be a continuous and increasing monotonic function. Departures from this behaviour denote that some intervening phenomena have not been considered or have been underestimated. In Fig. 1 the behaviour of $E(t)$, obtained from Eqn. (4) for the daily mean of the calibrated data, collected at Pallanzeno for a soil column of height $\mathrm{H}=50 \mathrm{~cm}$ (all the horizontal probes), can be seen. In the figure $E(t)$ is expressed in centimetres, numerically equal to the units of Eqn. (4), mass per cross section equal to one, the water density being $1000\left(\mathrm{~kg} \mathrm{~m}^{-3}\right)$. Owing to the lack of the data from May, $E(t)$ is represented by two pieces of curve; the first is for April, the second for the data from June to November. The behaviour is essentially monotonic and continuous except for the decrease in April and the steep increases coinciding with the two heavy precipitation events at the end of September and October. The minimum in $E(t)$ during the precipitation event in April indicates that the neglected fluxes are significant. The two step-like increases in September and October suggest that the total water precipitated is much greater than the increase in the water content of the first $50 \mathrm{~cm}$ of soil; therefore, if the infiltration rate is exceeded, the surface water excess accumulates, forming puddles and perhaps runoff.

During the summer period, the mean daily evaporation is about $4 \mathrm{~mm}$ a day (see the linear regression of Fig. 1) whereas a lower value (about $2.5 \mathrm{~mm}$ a day) was found in April. The cumulative function $E(t)$ also indicates that the evaporation is mainly atmosphere-limited but periods of soil-limited evaporation can be distinguished (e.g. end of July and before the heavy precipitation of September 20 and October 21) (Hillel, 1980; Brutsaert and Chen, 1995).

\section{Soil physical characteristics}

The soil physical properties and pedological characteristics of the Pallanzeno site were obtained from measurements in situ, in the laboratory at the University of Brescia (Falappi et al., 2000) and at the Istituto Agrario di San Michele all'Adige (ISMA) (Eccel et al., 2000).

The soil water content characteristic and the unsaturated hydraulic conductivity can be described respectively by the following power functions (Campbell, 1985)

$$
\psi=\psi_{s}\left(\frac{\theta}{\theta_{s}}\right)^{-b} \quad k=k_{s}\left(\frac{\theta}{\theta_{s}}\right)^{2 b+3}
$$

where $\Psi_{s}$ is the air entry potential; $\theta_{s}$ is the water content at saturation; $k_{s}$ is the saturated hydraulic conductivity of the soil. $\Psi_{s}$ and $b$ are derived from the offset and the slope of the log-log soil water retention function. From the soil samples collected at Pallanzeno, three soil water retention functions were obtained for three different layers $(0-10,10$ $20,20-40 \mathrm{~cm}$ ) (see Fig. 5). The values of $\Psi_{s}$ and $b$ for the three previously quoted layers are reported in Table 3 .

The hydraulic conductivity at the saturation $\left(k_{s}\right)$ of the layer $(0-14 \mathrm{~cm})$ was measured in the laboratory; the value for a deeper layer was obtained by an in situ infiltration test. The real value of $k_{s}$ is expected to be between the measured values reported in Table 4 and most likely closer to the laboratory value, owing to the difficulties related to 
Table 3. Values of the air entry potential $\Psi_{\mathrm{s}}$ and the exponent $\mathrm{b}$ of power functions (5) for the three different layers 0-10, 10-20, 20-40 cm of soil sampled at Pallanzeno.

\begin{tabular}{lll}
\hline Depth $(\mathrm{cm})$ & Air entry potential $\Psi_{s}(\mathrm{~m})$ & $b$ \\
\hline $0-10$ & -0.33 & 4.2 \\
$10-20$ & -0.14 & 4.3 \\
$20-40$ & -0.07 & 4.6 \\
\hline
\end{tabular}

Table 4. Hydraulic parameters and physical properties of the Pallanzeno soil obtained both in situ and in laboratory (from Falappi et al., 2000).

\begin{tabular}{ll}
\hline Parameter & Value \\
\hline$k_{s}$ (laboratory) & $2.2610^{-7}\left(\mathrm{~m} \mathrm{~s}^{-1}\right)$ \\
$k_{s}$ (in situ) & $1.8910^{-4}\left(\mathrm{~m} \mathrm{~s}^{-1}\right)$ \\
$\rho_{b}$ (bulk density) & $1.0510^{3}\left(\mathrm{~kg} \mathrm{~m}^{-3}\right)$ \\
$\rho_{p}$ (particle density) & $2.6610^{3}\left(\mathrm{~kg} \mathrm{~m}^{-3}\right)$ \\
$\phi$ (porosity) & 0.61 \\
$\theta_{s}=0.925 \phi$ & 0.562 \\
$\theta_{\max }$ (measured) & $56(\%)$ \\
\hline
\end{tabular}

Table 5. Texture analysis of the Pallanzeno soil samples. Classification of soil according to the U.S. Soil Survey Methodology (from Eccel et al., 2000).

\begin{tabular}{lccll}
\hline $\begin{array}{l}\text { Depth } \\
(\mathrm{cm})\end{array}$ & $\begin{array}{l}\text { Sand } \\
(\%)\end{array}$ & $\begin{array}{l}\text { Silt } \\
(\%)\end{array}$ & $\begin{array}{l}\text { Clay } \\
(\%)\end{array}$ & Textural class \\
\hline $0-10$ & 31.0 & 56.9 & 12.1 & Silt Loam \\
$10-20$ & 35.0 & 62.6 & 2.4 & Silt Loam \\
$20-40$ & 40.1 & 57.6 & 2.3 & Silt Loam \\
\hline
\end{tabular}

the in situ test (Falappi et al., 2000). The soil water content at the saturation $\left(\theta_{s}\right)$ was assumed to be equal to $92.5 \%$ of porosity (Van Genuchten et al., 1991); this value equals the maximum soil water content measured at Pallanzeno during the IOP-02 (see Table 4). The physical properties of the soil are reported in Table 4 (Falappi et al., 2000) and the textural composition of the soil is reported in Table 5 (Eccel et al., 2000)).

\section{Soil water content trend during the driest period}

The soil water content is a function of space and time: considering only the vertical direction, its time and space evolution can be obtained by solving the one dimensional
Richards equation. Defining the hydraulic diffusivity as $D=k \cdot \partial \psi / \partial \theta$, the Richards equation can be written as

$$
\frac{\partial \theta}{\partial t}=\frac{\partial}{\partial z}\left(D \cdot \frac{\partial \theta}{\partial z}\right)-\frac{\partial k}{\partial z}
$$

Since D and $k$ depend on $\theta$, Eqn. (6) is strongly non-linear. It is well known that numerical solutions are suitable and powerful in solving non-linear equations starting from the experimental initial and boundary conditions (Montaldo et $a l ., 2000)$. This appears to be quite appropriate when solving specific problems such as infiltration of water into initially dry soil. On the other hand, the analytical solutions provide general insights and identify the relationships among the variables of the problem under study. Furthermore, they can be useful to validate numerical schemes (Basha, 1999; Hogarth and Parlange, 2000; Chen et al., 2001).

Here, a particular case of soil drying is presented, based on the data collected at Pallanzeno treated both numerically and analytically.

On 19 July 1999, the distribution of the experimental soil volumetric water content in the first $40 \mathrm{~cm}$ soil layer was quite uniform. This distribution represents a simple initial condition for solving the partial differential equation (Eqn. (6)). The soil layer below $40 \mathrm{~cm}$ remained at practically the same soil water content during the period 19-27 July.

Assuming Eqn. (5) to be valid and considering only one layer (from the surface down to $40 \mathrm{~cm}$ ) as having the mean soil physical characteristics derived from Table 3 and a mean $k_{s}$ equal to $310^{-6}\left(\mathrm{~m} \mathrm{~s}^{-1}\right)$, Eqn. (6) was numerically solved. The $k_{s}$ value used is between the measured values of the hydraulic conductivity reported in Table 4 and close to the laboratory estimation. The uniform initial condition and the upper and lower boundary conditions were obtained from the experimental data. Figure 6 a shows the results of the numerical solution of Eqn. (6); the evolution of the daily vertical profile of the soil water content from 19 to 27 July 1999 (driest period) is compared with the experimental data (circles). The numerical vertical profiles have been extrapolated, assuming a linear trend, from $5 \mathrm{~cm}$ to the soil surface.

Figure $6 \mathrm{~b}$ shows the water loss from a column of cross section equal to one and $40 \mathrm{~cm}$ height; the solid line is the cumulative loss computed from the numerical solution and the symbols represent that obtained from the experimental data. On the assumption that the loss of water is essentially from the soil to the atmosphere, this represents the cumulative evaporation (evapotranspiration).

To find analytical solutions, Eqn. (6) was linearised, i.e. $\mathrm{D}$ and $d k / d \theta$ were assumed constant, so obtaining the linearised Richards Eqn. (7) 


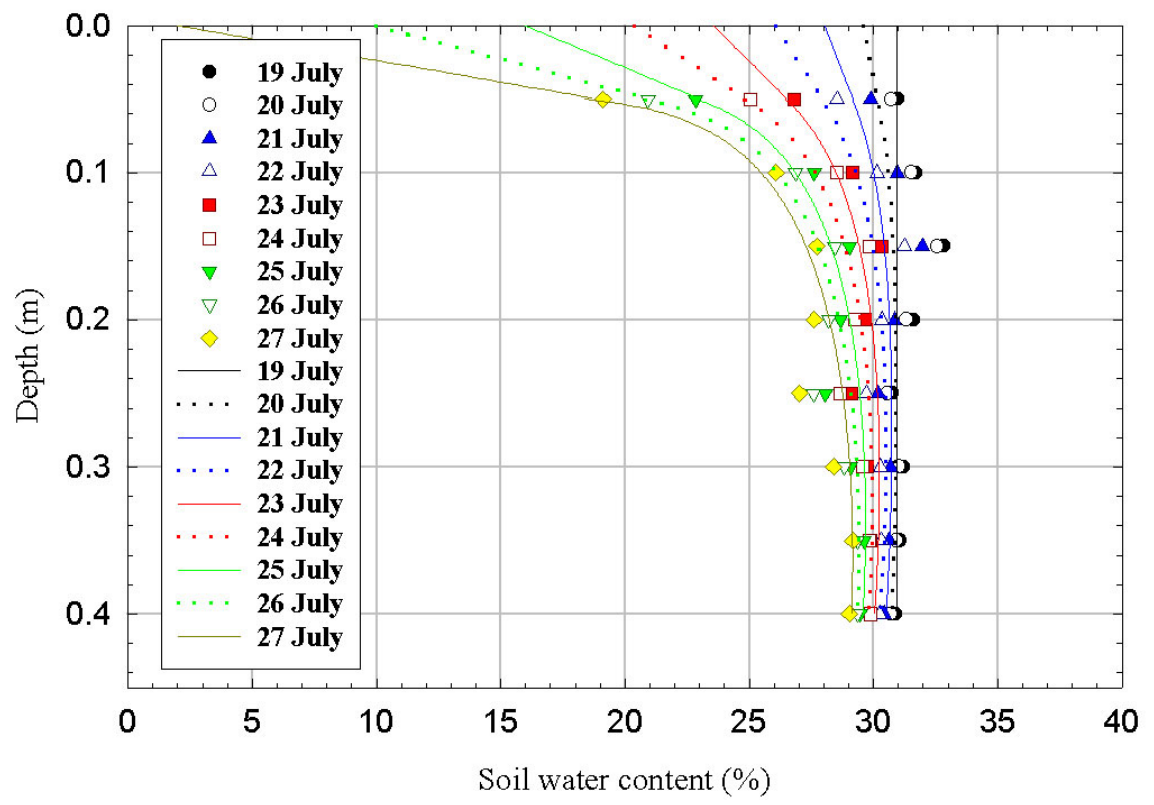

Fig. 6a. Evolution of the daily vertical profile of the soil water content from 19 to 27 July 1999 (driest period). The solid lines are obtained by the numerical solution of the Richards Eqn. (6); the symbols are the experimental data. The numerical profiles have been extrapolated, assuming a linear trend, from $5 \mathrm{~cm}$ to the soil surface.

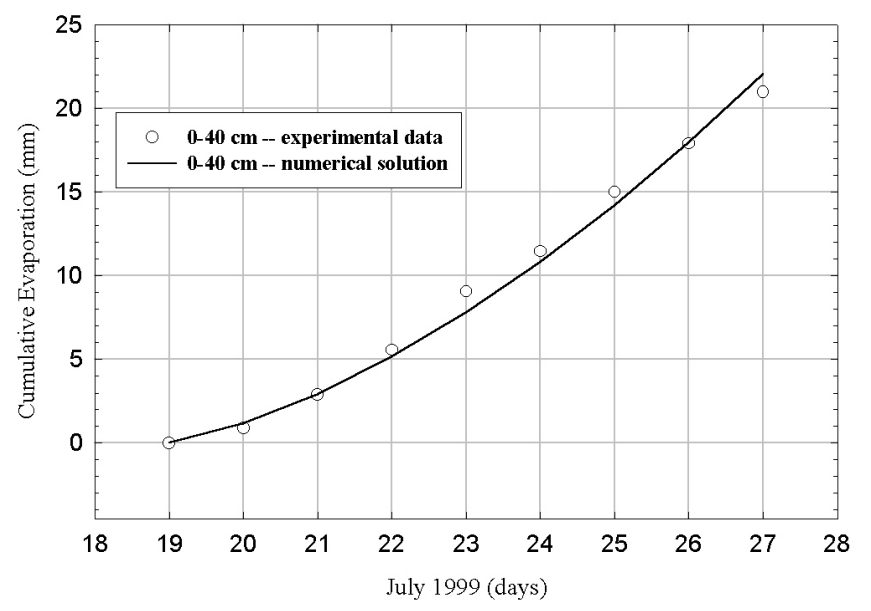

Fig. 6b. Water loss from a column of cross section equal to one and $40 \mathrm{~cm}$ height. The solid line is the cumulative loss computed from the numerical solution and the circles represent that obtained from the experimental data.

$$
\frac{\partial \theta}{\partial t}=\bar{D} \cdot \frac{\partial^{2} \theta}{\partial z^{2}}-k_{v} \frac{\partial \theta}{\partial z}
$$

where $\bar{D}$ and $k_{v}=d k / d \theta$ are two constants.

This simplification makes the equation analytically solvable for a large class of initial and boundary conditions, provided they are expressed by simple functions interpolating the experimental data.

The mean diffusivity to be used to solve Eqn. (7) must characterise the drying process and, according to Crank (1956), the weighted mean diffusivity for desorption processes is

$$
\bar{D}=\frac{1.85}{\left(\theta_{i}-\theta_{f}\right)^{1.85}} \cdot \int_{\theta_{f}}^{\theta_{i}} D(\theta) \cdot\left(\theta_{i}-\theta\right)^{0.85} d \theta
$$

where $\theta_{i}$ is the initial value of the uniform wetness profile and $\theta_{f}$ is the final value of the surface wetness.

The hydraulic diffusivity in Eqn. (8) has been expressed through the relationships given in Eqn. (5). The soil was considered as a uniform layer from the surface to $40 \mathrm{~cm}$, having the mean soil physical characteristics derived from Table 3 . The hydraulic conductivity $\left(k_{s}\right)$ was assumed equal to $310^{-7}\left(\mathrm{~m} \mathrm{~s}^{-1}\right)$, i.e. about the same as the laboratory estimation, see Table 4 (this value is one order of magnitude lower than the value previously used to compute the numerical solution). Finally, assuming the following initial and final values ( $\theta_{i}=0.4$ and $\left.\theta_{f}=0.1\right)$ for the soil water content and taking into account that $4<b<5$, the mean diffusivity is about $10^{-9}\left(\mathrm{~m}^{2} \mathrm{~s}^{-1}\right)$.

The second term on the right of Eqn. (7) can be regarded as a negative source term proportional to the vertical gradient of the soil water content and can be considered as the contribution of the vapour phase. The constant $k_{v}$ has the dimension of a velocity. The following function (9) is the analytical solution of Eqn. (7),

$$
\theta=\theta_{i}-\frac{\theta_{i}}{2} \cdot \operatorname{erfc}\left(\frac{z-k_{v} \cdot t}{\sqrt{4 \cdot \bar{D} \cdot t}}\right)+\frac{\theta_{i}}{2} \cdot e^{k_{v} \cdot z / \bar{D}} \cdot \operatorname{erfc}\left(\frac{z+k_{v} \cdot t}{\sqrt{4 \cdot \bar{D} \cdot t}}\right)
$$


which implies a uniform initial condition and the boundary condition at $z=0$ described by

$$
\theta(z=0, t)=\theta_{i} \cdot \operatorname{erfc}\left(\sqrt{\frac{k_{v}^{2} \cdot t}{4 \cdot \bar{D}}}\right)
$$

Figure 7a shows the evolution (19 to 27 July 1999) of the daily vertical profile of the soil water content obtained from the analytical solution (Eqn. (9)). The solution shown in Fig. 7a was obtained using $\bar{D}=510^{-9}\left(\mathrm{~m}^{2} \mathrm{~s}^{-1}\right)$ and $k_{v}=10^{-7}$ $\left(\mathrm{m} \mathrm{s}^{-1}\right)$. The symbols are the experimental data. The agreement between the theoretical curves and the experimental data is satisfactory mainly in the upper part of the soil layer $(0-15 \mathrm{~cm})$. The discrepancy in the underlying layer may be due to the quite large range of $\theta$ in this drying process which reduces the validity of the linearised equation. Furthermore, the soil layer was considered homogeneous while some non-homogeneities exist, as can be seen from the data in Table 5. Figure $7 \mathrm{~b}$ shows the water loss from a column of cross section equal to one and only $15 \mathrm{~cm}$ height; the solid line is the cumulative loss computed from the analytical solution and the circles represent that obtained from the experimental data.

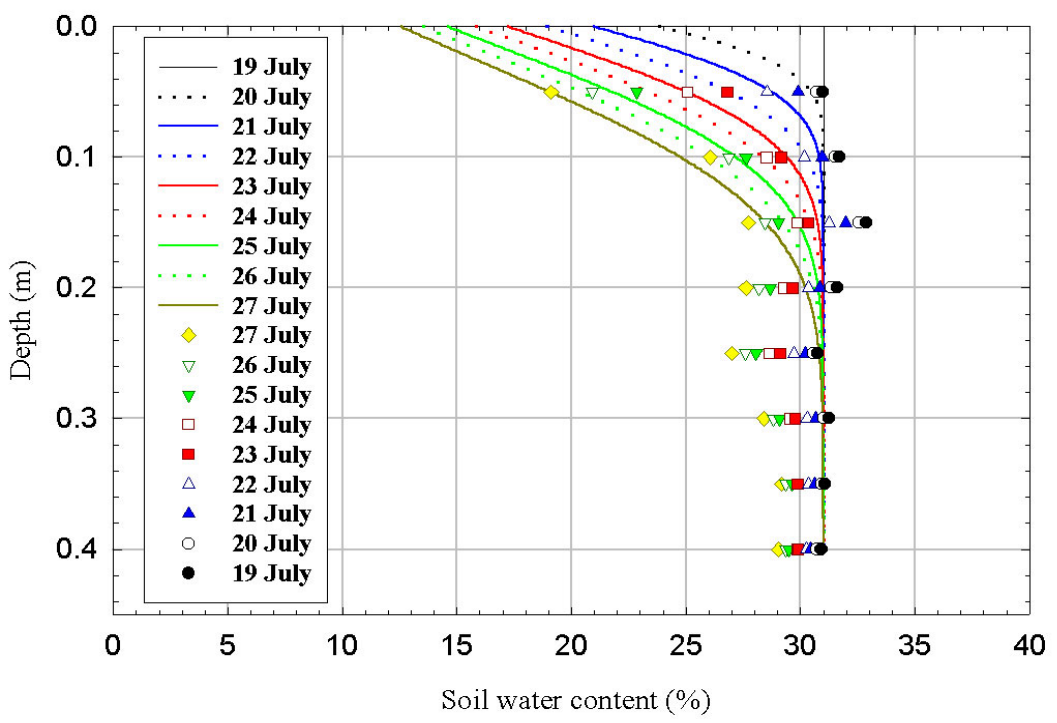

Fig. 7a. Evolution of the daily vertical profile of the soil water content from 19 to 27 July 1999 (driest period). The solid lines are obtained by the analytical solution of equation (7); the symbols are the experimental data.

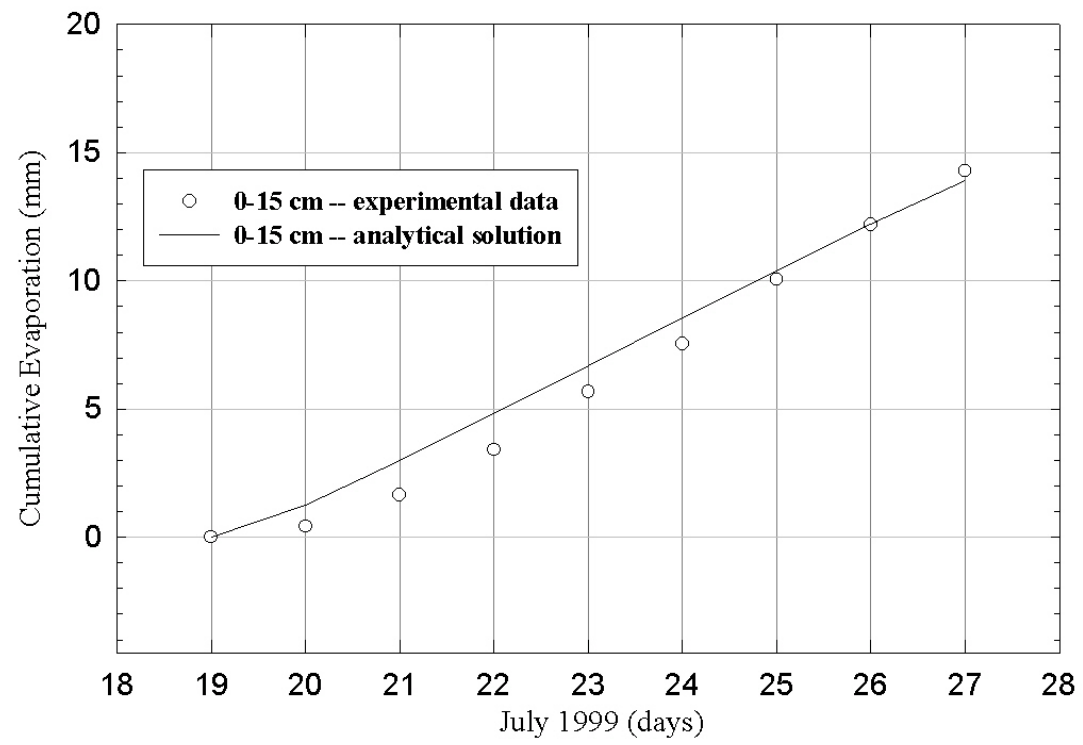

Fig. 7b. Water loss from a column of cross section equal to one and only $15 \mathrm{~cm}$ height. The solid line is the cumulative loss computed from the analytical solution and the circles represent the one obtained from the experimental data. 


\section{Soil water content trend during the IOP-02}

The heaviest precipitation event of the SOP took place during the IOP-02 (225.4 $\mathrm{mm}$ in about 36 hours). In Fig. $8 \mathrm{a}$, the symbols are the soil water content profiles measured at a four-hour time step, from 19 September at 16:00 to 20 September at 8:00; i.e. the first part of the IOP-02. From an almost uniform initial profile of about 33\% (September 19 at 16:00), the soil water content at the surface increased steeply to about $50 \%$ after four hours (one time step). In the same figure a wetting front, localised where the moisture gradient is the steepest (inflection point), can be envisaged moving down the soil profile. Equation (11) is the solution of Eqn. (7) obtained by assuming a uniform initial condition $\theta=\theta_{i}$ and $\theta(z=0, t>0)=\theta_{f}$ as boundary condition.

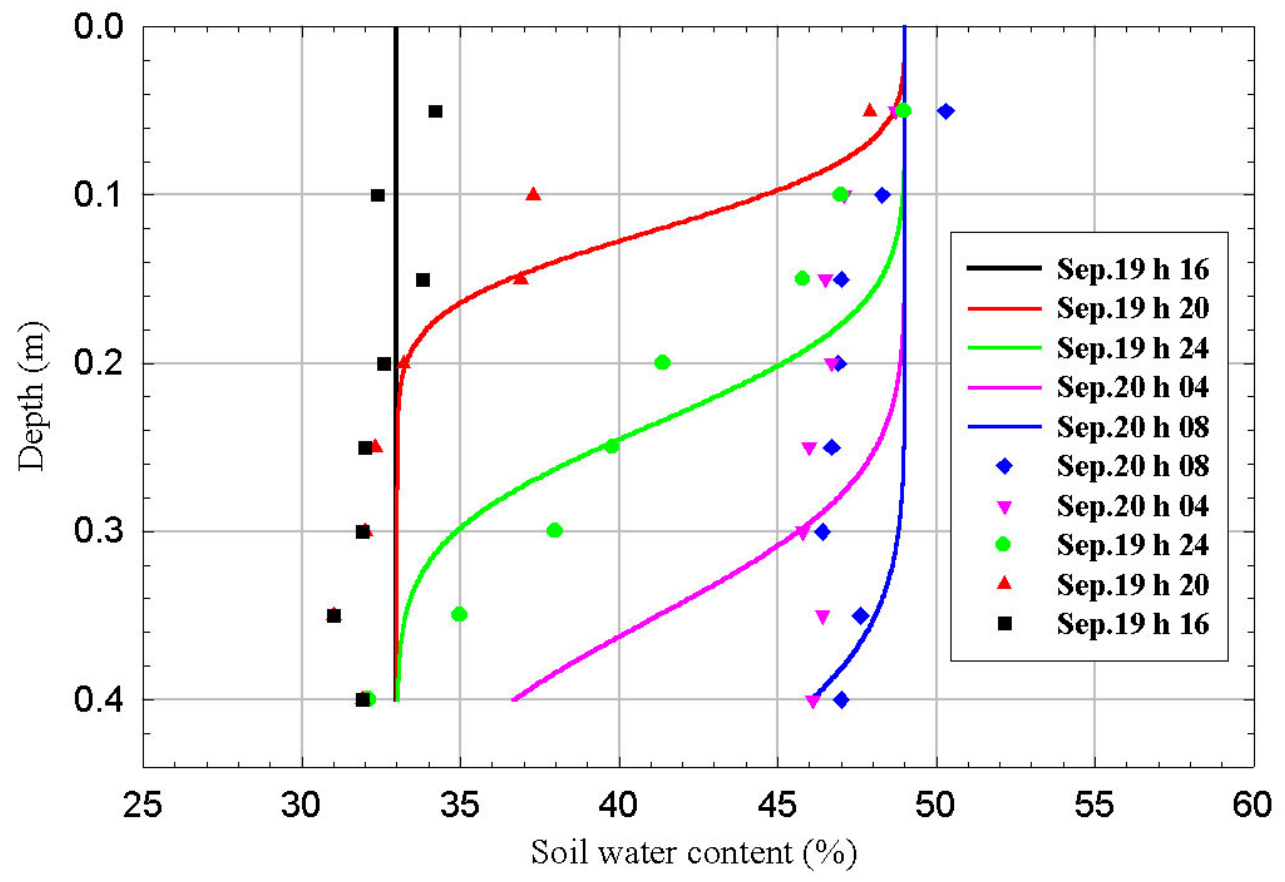

Fig. 8a. Evolution of soil water content in the first $40 \mathrm{~cm}$ layer from September 19, 4 pm to September 20, 8 am. The experimental profiles (symbols) are compared with the theoretical results (solid lines) obtained from the analytical solution (11).

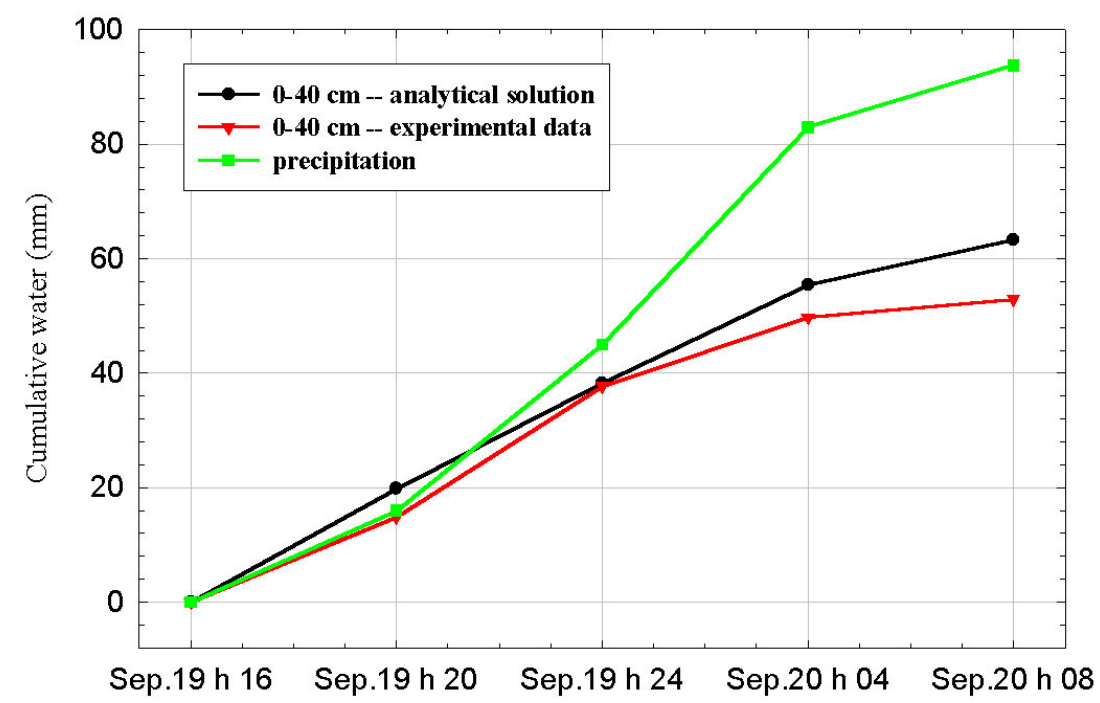

Fig. $8 \mathrm{~b}$. The three curves represent the measured precipitated water (square), the water accumulated in a column of cross-section equal to one and $40 \mathrm{~cm}$ height computed from the analytical solution (11) (circle) and that computed from the experimental data (triangle). 
$\theta=\theta_{f}-\frac{\theta_{f}-\theta_{i}}{2} \cdot \operatorname{erfc}\left(\frac{k \cdot t-z}{\sqrt{4 \cdot \bar{D} \cdot t}}\right)+\frac{\theta_{f}-\theta_{i}}{2} \cdot e^{k \cdot z / \bar{D}} \cdot \operatorname{erfc}\left(\frac{k \cdot t+z}{\sqrt{4 \cdot \bar{D} \cdot t}}\right)$

As this is a sorption case, the gravity term has been taken into account. The constant term $k$ (named $k_{v}$ in Eqn. (7)) is related to the velocity of the wetting front. In fact, the second derivative of the function expressed by Eqn. (11) equals zero in a point located in the range $k \cdot t<z<2 \cdot k \cdot t$. This implies the presence of an inflection point (wetting front), which moves downwards with a velocity derivable from the following transcendental equation

$$
\frac{2 \cdot k \cdot t-z}{k^{2} \cdot t \cdot \sqrt{\frac{\pi \cdot t}{\bar{D}}}}=e^{\left(\frac{k \cdot t+z}{\sqrt{4 \cdot \bar{D} \cdot t}}\right)^{2}} \cdot \operatorname{erfc}\left(\frac{k \cdot t+z}{\sqrt{4 \cdot \bar{D} \cdot t}}\right)
$$

The velocity of the wetting front given by Eqn. (12) approaches $2 k$ for the time approaching zero (start of infiltration) and reduces to $k$ as the time increases. Using the soil characteristics of Pallanzeno, the velocity of the wetting front is almost equal to $k$ after four hours from the start of infiltration. The constant mean diffusivity, $\bar{D}$, has been computed using a relationship similar to Eqn. (8) but suitable for the infiltration process (Crank, 1956). As for the dry case, the soil was considered as a uniform layer from the surface to $40 \mathrm{~cm}$, having the mean soil physical characteristics derived from Table 3 and the same hydraulic conductivity value $\left(k_{s}=310^{-7} \mathrm{~m} \mathrm{~s}^{-1}\right)$. Considering the following initial and final values $\left(\theta_{i}=0.2\right.$ and $\left.\theta_{f}=0.5\right)$ for the soil water content, and taking into account that $4<b<5$, the mean diffusivity is about $510^{-8}\left(\mathrm{~m}^{2} \mathrm{~s}^{-1}\right)$.

In Fig. 8a, the experimental profiles (see legend) are compared with the theoretical results (solid lines) obtained from Eqn. (11) using $\bar{D}=5 \cdot 10^{-8}\left(\mathrm{~m}^{2} \mathrm{~s}^{-1}\right)$ and $k=8 \cdot 10^{-6}$ $\left(\mathrm{m} \mathrm{s}^{-1}\right)$. The first experimental profile (September 19 at 16:00) is the last collected just before the precipitation. Figure $8 \mathrm{a}$ shows the evolution of the soil water content in the first $40 \mathrm{~cm}$ layer from $4 \mathrm{pm}$ on September 19 to 8 am on September 20. The water precipitated during this period $(92.7 \mathrm{~mm})$ produced the major change in the superficial soil water content and caused the soil to reach almost complete saturation at the surface. The water precipitated in the second part of the event produced only a minor increase in the superficial soil water content. The agreement between the theoretical and experimental data is good for the first $40 \mathrm{~cm}$ but is not so satisfactory in the lower part (not shown). On the other hand, the initial soil water content is almost uniform only in the first $40 \mathrm{~cm}$ layer. In general, the discrepancies may be attributed to inaccuracy in the hydraulic characterisation of the soil and to the reasons discussed earlier.
Figure $8 \mathrm{~b}$ shows the water accumulated in a column of cross section equal to one and $40 \mathrm{~cm}$ height. The three curves represent: the water accumulated in the quoted column computed from the analytical solution (11; circle), the value computed from the experimental data (triangle) and the measured precipitated water (square). From Fig. 8b, it is evident that the water precipitated during these 16 hours is greater than the water accumulated in the first $40 \mathrm{~cm}$ of soil. As the soil water content under the first $40 \mathrm{~cm}$ of soil is not constant, part of the precipitated water is responsible for this increase. However, as the mean precipitation rate in the considered 16 hours is $1.610^{-6}\left(\mathrm{~m} \mathrm{~s}^{-1}\right)$, which seems to be greater than the steady infiltrability $\left(k_{s}\right)$, part of the precipitated water may remain on the surface, producing ponding or runoff. On the other hand, the experimental profiles reported in Fig. 8a well represent the distribution of water during the infiltration process under ponded conditions (Hillel, 1980). From the bottom to the top, it can be seen firstly the wetting front and the wetting zone where the water content sharply increases and secondly, the transmission zone characterised by a fairly constant value for the water content. The transition zone and the saturated zone are most likely localised nearest the surface (the first $5 \mathrm{~cm}$ ) where no experimental data are available.

\section{Conclusions}

The high precision of the soil water content measurements performed by the TDR technique enables these data* to be used as calibration for other techniques. During MAP-SOP TDR readings were used as ground truth for the remotely sensed data obtained by the aforementioned microwave passive radiometer on board a helicopter.

The experimental readings show a daily cycle in the volumetric water content. On the basis of a laboratory experiment, it is postulated that this daily oscillation depends both on soil temperature and, in particular, on the instrument temperature. From the laboratory experiment, a linear relationship was found between the change in soil water content and the temperature (of the soil and of the instrument).

Some results such as cumulative evaporation have been obtained directly from the measured soil water content and can be verified by atmospheric measurements performed by the boundary layer stations (e.g. eddy correlation and/or Bowen ratio methods).

Both dry and wet cases have been considered. In particular, the dry cases are important for understanding the

\footnotetext{
* These data are part of a complete data set for the catchment and are available at the MAP Data Centre (http://www.map.ethz.ch/).
} 
second stage of evaporation, i.e. the soil-limited process. These cases, characterised by a cumulative evaporation proportional to the square root of time, show a short duration in this particular experiment owing to the peculiar climatic characteristics of this area. The wet cases are very important for predicting runoff and flooding because of the influence of the antecedent precipitation on resulting soil water content.

\section{Acknowledgements}

Electrical-Energy Industry (ENEL) is thanked for permission to install instrumentation on their property, for use of the rain gauge data and for help given throughout the measurement period. This work was partly funded by the Italian National Research Council (CNR) and the Ministry of the University and Scientific and Technological Research (MURST).

\section{References}

Basha, H.A., 1999. Multidimensional linearized nonsteady infiltration with prescribed boundary conditions at the soil surface. Water Resour. Res., 35, 75-83.

Binder, P. and Schär, C., (Eds.), 1996. MAP Design Proposal. Schweizerische Meteorologische Anstalt, Krähbühlstrasse 58, CH-8044 Zürich, Switzerland.

Bougeault, P., Binder, P. and Kuettner, J. (Eds.), 1998. MAP Science Plan. MAP Data Centre, http://www.map.ethz.ch/splan/ spindex.htm.

Brutsaert, W. and Chen, D., 1995. Desorption and the two stages of drying of natural tallgrass prairie. Water Resour. Res., 31, $1305-1313$.

Cahill, A.T. and Parlange, M.B., 1998. On water vapor transport in field soils. Water Resour. Res., 34, 731-739.

Campbell, G.S., 1985. Soil physics with BASIC. Elsevier, The Netherlands.

Chen, J.-M., Tan, Y.-C., Chen, C.-H. and Parlange, J.-Y., 2001. Analytical solutions for linearized Richards equation with arbitrary time-dependent surface fluxes. Water Resour. Res., 37, 1091-1093.

Crank, J., 1956. The mathematics of diffusion. Oxford University Press, London and New York.

Eccel, E., Toller, G. and Sicher, L., 2000. Field and laboratory soil measurements in the Toce Valley (Italy), during the MAPSOP 1999 TOCEX experiment: the contribution of ISMA. In: Hydrological aspects in the Mesoscale Alpine Programme-SOP experiment, R. Ranzi and B. Bacchi (Eds.). Univ. of Brescia, Dept. of Civil Engineering, Technical Report N. 10, 2000. available at http://bsing.ing.unibs.it/ dic-segr/maphyd.htm

Falappi L., Barontini, S., Clerici, A., Grossi, G., Savoldi, E. and Ranzi, R., 2000. Field and laboratory soil measurements in the Toce Valley (Italy), during the MAP-SOP 1999 TOCEX experiment. In: Hydrological aspects in the Mesoscale Alpine Programme-SOP experiment, R. Ranzi and B. Bacchi (Eds.). Univ. of Brescia, Dept. of Civil Engineering, Technical Report N. 10, 2000. available at http://bsing.ing.unibs.it/ dic-segr/ maphyd.htm
Heimovaara, T.J., 1993. Time domain reflectometry in soil science: theoretical background, measurements, and models. Ph.D thesis, University of Amsterdam, The Netherlands.

Heimovaara, T.J. and de Water, E., 1993. A computed controlled TDR system for measuring water content and bulk electrical conductivity of soils. Report No. 41, Laboratory of Physical Geography and Soil Science, University of Amsterdam, The Netherlands.

Hillel, D., 1980. Applications of Soil Physics. Academic Press, New York.

Hogarth, W.L. and Parlange, J.Y., 2000. Application and improvement of a recent approximate analytical solution of Richards' equation. Water Resour. Res., 36, 1965-1968.

Montaldo, N., Toninelli, V., Mancini, M., Albertson, J.D. and Troch, P. A., 2000. Estimation of actual evapotranspiration and soil moisture in the Pieve Vergonte case study. In: Hydrological aspects in the Mesoscale Alpine Programme-SOP experiment, R. Ranzi and B. Bacchi (Eds.). Univ. of Brescia, Dept. of Civil Engineering, Technical Report N. 10, 2000. available at http:// bsing.ing.unibs.it/ dic-segr/maphyd.htm

Or, D. and Wraith, J.M., 1999. Temperature effects on soil bulk dielectric permittivity measured by time domain reflectometry: A physical model. Water Resour. Res., 35, 371-383.

Or, D. and Wraith, J.M., 2000. Comment on "On water vapor transport in field soils" by Anthony T. Cahill and Mark B. Parlange. Water Resour. Res., 36, 3103-3105.

Paloscia, S., Macelloni, G., Pampaloni, P., Santi, E. and Ruisi, R., 2000. Monitoring of soil moisture and vegetation biomass in the Toce Valley. In: Hydrological aspects in the Mesoscale Alpine Programme-SOP experiment, R. Ranzi and B. Bacchi (Eds.). Univ. of Brescia, Dept. of Civil Engineering, Technical Report N. 10, available at http://bsing.ing.unibs.it/ dic-segr/ maphyd.htm

Pepin, S., Livingstone, N.J. and Hook, W.R., 1995. Temperaturedependent measurement errors in time domain reflectometry determinations of soil water. Soil Sci. Soc. Amer. J., 59, 38-43.

Roth, K., Schulin, R., Fluhler, H. and Attinger, W., 1990. Calibration of Time Domain Reflectometry for water content measurement using a composite dielectric approach. Water Resour. Res., 26, 2267-2273.

Soilmoisture, 2000. 6050X1 Operating Instructions, Soilmoisture Equipment Corporation, 801 S. Kellogg Ave., Goleta, CA 93117 , USA.

Topp, G.C., Davis, J.L. and Annan, A.P., 1980. Electromagnetic determination of soil water content: measurements in coaxial transmission lines. Water Resour. Res., 16, 574-582.

Van Genuchten, M.Th., Leij, F.J. and Yates, S.R., 1991. The RETC code for quantifying the hydraulic functions of unsaturated soils, Version 1.0. EPA Report 600/2-91/065, Ada, Oklahoma, USA.

Wraith, J.M. and Or, D., 1999. Temperature effects on soil bulk dielectric permittivity measured by time domain reflectometry: Experimental evidence and hypothesis development. Water Resour. Res., 35, 361-369. 